\title{
OS LIMITES REGULAMENTADORES DA PROPAGANDA ELEITORAL NO ÂMBITO DAS REDES SOCIAIS A PARTIR DA TEORIA DOS SISTEMAS AUTOPOIÉTICOS
}

\author{
Eduardo Hoffmann* \\ Lucas Paulo Orlando de Oliveira* \\ Leonel Severo Rocha**
}

\begin{abstract}
Resumo:
Diante do contexto complexo da globalização, a formatação dogmática jurídica da modernidade, que legitimava o Estado-nação como detentor do monopólio de produção regulatória, já mais corresponde à necessidade de estruturação das relações sociais. Tem-se na Teoria dos Sistemas Sociais Autopoiéticos uma forma de compreensão da atual realidade contingente e complexa, que pode servir de balizamento para as relações entre o direito e as redes sociais, especialmente no âmbito da propaganda eleitoral nas redes sociais, como o Facebook e o Twitter.
\end{abstract}

Palavras-chave: Propaganda eleitoral; Teoria dos Sistemas Sociais; Pluralismo Jurídico; Princípio da Sustentabilidade; Redes Sociais.

\section{THE REGULATORY LIMITS OF ELECTORAL ADVERTISING IN THE FRAMEWORK OF SOCIAL NETWORKS FROM THE THEORY OF AUTOPOIETIC SYSTEMS}

\begin{abstract}
:
Faced with the complex context of globalization, the modern legal dogmatic formation, that legitimized nation-state as the holder of a monopoly of regulatory production, already corresponds to the need for structuring social relations. It is a theory of autopoietic social systems, a way of understanding the current contingent and complex reality, which can serve as

\footnotetext{
* Doutorando em Direito pela Universidade do Vale dos Sinos (Unisinos), linha de Hermenêutica, Constituição e Concretização de Direitos (2019). Professor no Centro Universitário FAG. eduardohoffmann@ hotmail.com.

* Doutorando em Direito pela Universidade do Vale dos Sinos (Unisinos), linha de Hermenêutica, Constituição e Concretização de Direitos (2019). Membro do Grupo de Estudos Culturas Jurídicas Comparadas, Internacionalização do Direito e Sistemas de Justiça: atores, fatores e processos entre mundialização e cosmopolitismo jurídico, da Universidade do Vale do Rio dos Sinos. Professor no Centro Universitário FAG. Lucasoliveira@fag.edu.br.

** Possui graduação em Ciências Jurídicas e Sociais pela Universidade Federal de Santa Maria (1979), Mestrado em Direito pela Universidade Federal de Santa Catarina (1982), Doutorado pela Ecole des Hautes Etudes en Sciences Sociales de Paris (1989), Revalidado como Doutor na área do Direito, pela UFSC, em 13/02/2003, conforme processo 23080.025472/2002-06 e Resolução n.01/CNE/2001 ) e Pós-doutorado em Sociologia do Direito pela Universita degli Studi di Lecce - Itália. Atualmente é Professor Titular da Universidade do Vale do Rio dos Sinos, bem como Professor do PPGD da Universidade Regional Integrada do Alto Uruguai (URI),onde Coordena a Catedra Warat; Professor Visitante da Faculté de Droit da Universidade de Paris 1. Bolsista Produtividade do CNPq. Foi Coordenador Executivo (2012-2018 ) do Programa de Pós-Graduação em Direito da Unisinos (Mestrado e Doutorado, Capes 6).
} 
a balance for the relations between rights and social networks, especially with regard to electoral advertising on social networks, such as Facebook and Facebook and Twitter.

Keywords: Electoral advertising; Theory of Social Systems; Legal pluralism; Principle of Sustainability; Social networks.

\section{Introdução}

A Internet surge para o uso militar a partir da década de 1960. Nas décadas de 1970 e 1980 acaba por ganhar aplicações na seara acadêmica. Por fim, na década de 1990 em diante se difunde o uso comercial e doméstico. Foi em 1991 que a primeira conexão com a internet ocorreu em solo brasileiro e a partir de 1995 que se estruturou o uso do domínio “.br” para a difusão em escala (BRASIL, 201?).

Por certo que a conexão entre diferentes usuários não apenas permitiu a intensificação das relações sociais, mas as ressignificou de um modo irreversível. Assim, é possível afirmar que a produção de conhecimento, as relações econômicas e o próprio direito possuem uma operacionalidade que se aproxima cada vez mais da lógica de funcionamento da rede (HJARVARD, 2014).

Entre essas várias mudanças estruturais, também a disputa eleitoral sofreu alterações sensíveis a partir do avanço da internet e das redes sociais, como o Facebook e o Twitter, que serão especialmente consideradas para os fins deste estudo, apesar de não serem as únicas.

Um dos elementos que podem ser assinalados, a título introdutório, como forma de corroborar a mudança anteriormente destacada, é a promulgação da Lei 12.034/2009 que acrescentou o art. 57-B na Lei 9.504/97 e regulamentou, mais especificamente em seu inciso IV, a possibilidade de realização de propaganda eleitoral por redes sociais no Brasil. ${ }^{1}$ Desse modo, aproximadamente 14 anos após o início do uso comercial da internet no Brasil houve a regulamentação oficial do debate eleitoral, em sentido amplo, no âmbito das redes sociais.

Tem-se na prática de propaganda eleitoral uma ferramenta diretamente associada à efetivação dos direitos políticos no Brasil, porque viabiliza o acesso do candidato a seus eleitores e vice-versa, além de promover o contraste dos diferentes projetos de sociedade que são discutidos em um pleito. Então, é possível considerar que as novas tecnologias na área da

\footnotetext{
${ }^{1}$ Art. 57-B. A propaganda eleitoral na internet poderá ser realizada nas seguintes formas: (...) IV - por meio de blogs, redes sociais, sítios de mensagens instantâneas e aplicações de internet; assemelhadas cujo conteúdo seja gerado ou editado por: a) candidatos, partidos ou coligações; ou b) qualquer pessoa natural, desde que não contrate impulsionamento de conteúdos.
} 
comunicação exercem papel importantíssimo no processo de disputa eleitoral (GOMES, $2019)^{2}$

Mas, se por um lado, a dinâmica das redes sociais afetou tanto o processo eleitoral, será que o direito está preparado para suas possibilidades e limites diante dessa nova realidade? A propaganda eleitoral nas redes sociais é sintomática dos novos tempos que desafiam as concepções tradicionais da dogmática jurídica, uma vez que o debate realizado neste espaço muitas vezes extravasa as possibilidades do poder regulatório e de fiscalização, em suas concepções tradicionais, que o Estado brasileiro, estruturado por elementos teóricos da modernidade, possui.

A título ilustrativo, é muito mais simples a realização da fiscalização dos conteúdos veiculados em uma emissora televisiva ou de radiodifusão do que em relação às páginas do Facebook ou mesmo às atividades de bots no Twitter ${ }^{3}$. Por certo que em relação às redes sociais os limites constituídos em para à imprensa tradicional não são aplicáveis, justamente porque a internet carrega consigo as marcas de um mundo globalizado, que opera de forma muito mais complexa, dinâmica e contingente do que aquela em que as estruturas primordiais do Estado-nação foram forjadas ${ }^{4}$ e que serviram para a tutela dos meios de comunicação desenvolvidos no mesmo período, mas que agora precisam ser repensadas.

Deste modo, no recorte temporal contemporâneo, é imperativo que a dogmática jurídica avance para novos contornos, de forma a estabelecer cada vez mais relações e interfaces com a Rede Mundial de Computadores, o que conduz a esforços constantes por parte dos juristas para adaptarem os conceitos jurídicos pretéritos ou criarem novas realidades conceituais a partir deste contexto (ROCHA, 2012).

Note-se que não se trata apenas de mais um espaço qualquer de regulamentação, mas sim de um locus onde ocorre a circulação de informações determinantes para a política

\footnotetext{
${ }^{2}$ Note-se que o que se pretende considerar não é uma análise a respeito do valor investido pelas campanhas em práticas como a de impulsionamento de conteúdo, efetivada nas eleições de 2018. O que se pretende evidenciar é a importância das redes sociais como espaço para a circulação de ideias entre os envolvidos, sejam candidatos, eleitores, partidos ou autoridades, em determinado pleito.

${ }^{3} \mathrm{O}$ uso de bots foi uma das preocupações ao longo do processo eleitoral de 2018, tanto é que a rede social chegou a anunciar medidas para enfrentar o uso dos perfis robotizados a serviço de táticas escusas de campanha eleitoral. Para mais informações conferir: https://blog.twitter.com/pt_br/topics/company/2017/twitter-detalha-medidascontra-uso-indevido-de-robos-e-desinformacao.html

${ }^{4}$ Neste sentido, a referência para os elementos caracterizadores da racionalidade do Estado-nação aqui referidas podem ser encontradas a partir da obra de BICCA, Luiz. Racionalidade, modernidade e subjetividade. São Paulo: Loyola, 1997.
} 
institucional e eleitoral, conforme destacado por Hjarvard (2014). Negligenciar este espaço não é mais uma alternativa aos candidatos de processos eleitorais ou as autoridades envolvidas.

Deste modo, o objetivo geral deste artigo é investigar elementos teóricos que auxiliem a compreensão do direito no mundo contemporâneo, de forma a viabilizar o delineamento de termos para a tutela jurídica da propaganda eleitoral no âmbito das redes sociais. Para tanto, será desenvolvida, em um primeiro momento, uma investigação a respeito dos conceitos basilares da teoria dos sistemas e, posteriormente, na segunda metade do trabalho, desenvolverse-ão elementos teóricos a partir de Gunther Teubner, especialmente a compreensão de pluralismo jurídico e do princípio da sustentabilidade para que se cumpra o referido desiderato.

A título de advertência, não se pretende extrair da aplicação dos postulados de Teuber uma única explicação ou alternativa para a superação do presente impasse. Tal pretensão seria uma grande incoerência em relação à compreensão dos sistemas sociais que tem a complexidade como um de seus elementos caracterizadores.

De modo diverso, o que se ambiciona é empregar o modelo teórico construído por Luhmann e Teubner para se compreender melhor o processo vivenciado na relação entre propaganda eleitoral e redes sociais. Tal esforço se contextualiza, assim, em uma ambição maior da ciência jurídica contemporânea ao, em certo sentido, contribuir para a identificação de elementos da relação entre direitos fundamentais, democracia e redes sociais.

\section{Aportes teóricos sobre a Teoria dos Sistemas Sociais Autopoiéticos}

O marco epistemológico do presente trabalho é delimitado a partir da compreensão da Teoria dos Sistemas Sociais Autopoiéticos, assim denominada por Rocha (1998), e concebida por Niklas Luhmann e, posteriormente, por Gunther Teubner entre outros, além do próprio Leonel Severo Rocha. Como objetivo desta primeira parte tem-se a definição dos principais conceitos referentes ao marco teórico selecionado, de modo a viabilizar a aplicação destes na segunda parte.

Sendo assim, em um primeiro momento é relevante que se defina o conceito de Sistema. Neste sentido, pode-se afirmar que o modelo teórico desenvolvido por Luhmann (2009) reconhece que os sistemas são constituídos a partir da diferença entre o sistema e meio. Tem-se na recursidade de uma operação o resultado de um sistema. Portanto, a diferenciação do meio é o elemento constitutivo estruturante do Sistema. Isto é, a repetição de várias 
operações de tipo próprio e diferenciadas do meio é o que permite constatar e definir um sistema no sentido empregado a partir deste modelo. É este o Princípio da Diferenciação que Luhmann (2009, p. 101) assinala como um paradoxo: "o sistema consegue produzir sua unidade, na medida em que realiza uma diferença".

Nesta perspectiva, a própria sociedade é concebida, conforme ressalta Losano (2011), como um sistema social composto de vários outros subsistemas. A partir da obra do próprio Luhmann (2005) é possível referendar como exemplos de subsistemas sociais a religião, a arte, a economia, a política e o direito.

Ainda segundo Luhmann (2009), cada um destes subsistemas que compõem a sociedade, entendida como sistema social, se desenvolve a partir de um encerramento operativo. Isto é, cada um dos subsistemas analisados produz um tipo de operação específica e autorreferencial que o permite se distinguir do meio. Precisamente, conforme sustentado por Rocha; Costa (2018), a autonomia operativa que cada subsistema possui é que se denomina como autopoiese. Assim, Luhmann (2009, p. 112) afirma que "dentro do sistema não existe outra coisa senão sua própria operação".

Mas se há o encerramento operativo, o que impede que o sistema apenas se autorreproduza sem que haja qualquer alteração de sua estrutura? Onde reside a possibilidade da mudança estrutural de um sistema? Para a resposta destas perguntas é necessário se atentar que, se por um lado, Luhmann (2009) sustenta que a premissa da autopoiese implica no reconhecimento de que as alterações no sistema só podem ocorrer em seu próprio interior e que dentro do sistema só há a própria operação, por outro lado, também reconhece o papel fundamental do meio para que as alterações estruturais no sistema ocorram.

Porém, tais alterações não podem se manifestar conforme uma concepção de razão gerida ao longo da modernidade. Isso porque as alterações são contingentes, não podem ser planejadas pelo sistema. Não existe sequer a possibilidade de que o sistema tenha acesso completo às informações do meio em virtude de seu encerramento operativo (LUHMANN, 2009).

Para explicar a possibilidade da mudança sistêmica, Luhmann (2009) recorre ao conceito de acoplamento estrutural. Explica o autor que a autopoiese não é capaz de, por si, permitir a evolução do sistema. É preciso que haja estímulos externos, isto é, a partir do meio. Porém, tal influência, não é possível de se constituir de forma causal, salvo se para a destruição do sistema influenciado. Assim, o sistema recebe a comunicação do meio externo, que pode ser 
convertida em irritação e ser assimilada de acordo com sua própria estrutura (ROCHA; COSTA, 2018).

Há, portanto, um limite no reconhecimento para a mudança. De acordo com Luhmann (2009), não é todo estímulo do meio que pode ser concebido como uma espécie de irritação ao sistema, uma vez que somente padrões altamente seletivos de informações ${ }^{5}$ do meio podem ser convertidos em estrutura por parte do mesmo, sem que isso leve à sua destruição. Deste modo, são os próprios elementos internos de um sistema que são os responsáveis por identificar os conteúdos informacionais do meio que guardam compatibilidade com a sua operação (LOSANO, 2011).

Em síntese, se reconhece que há uma abertura cognoscitiva, que, mesmo limitada, implica na possibilidade de que um sistema sofra estímulos e irritações do meio social, além de também, reciprocamente, permitir irritações em outros sistemas. É por esta abertura heterorreferente, pois parametrizada a partir do ambiente e não da própria estrutura do sistema, que informações são transformadas em lei no âmbito do direito, por exemplo (ROCHA; COSTA, 2018).

A título de exemplificação, para aplicar tais concepções no objeto de estudo do presente artigo, pondera-se que não foi o sistema jurídico que produziu a internet ou mesmo as redes sociais, mas é a partir do desenvolvimento destas redes e da comunicação social que se viabilizaram as afetações recíprocas entre os diversos subsistemas sociais, de tal forma a irritar também o direito e permitir que este, a partir de sua própria lógica, promova alterações na legislação eleitoral a respeito da propaganda no âmbito das redes sociais.

Um outro conceito que Luhmann emprega para a construção de seu sistema teórico é o da policontextualidade, que reconhece que em um mundo com tantos sistemas sociais diferenciados em comunicação recíproca constante, já não é mais possível pensar o Estado como único detentor da legitimidade para a elaboração de regulamentações. Essa limitação do poder regulamentar do Estado será fundamental para a compreensão do movimento seguinte.

Sob esse paradigma da Teoria dos Sistemas, conforme concebido por Teubner, também se torna necessário reavaliar a crença de que o Estado moderno é o detentor do monopólio do poder normativo, uma vez que conforme o próprio Luhmann (2004) já

\footnotetext{
${ }^{5}$ Aqui a linguagem aparece como "exemplo mais patente de padrões altamente seletivos" LUHMANN (2009, p. 134).
} 
reconhecia que o direito influencia e é influenciado pelos demais subsistemas sociais, bem como pelas comunicações que decorrem do meio.

Como continuador da obra de Luhmann, Teubner (2016) analisa as possibilidades que a teoria do direito apresenta para a compreensão da constituição no recorte contemporâneo. Assim, em um primeiro momento, considera que a constituição, como elaborada ao longo da modernidade, isto é, diretamente associada com o Estado-nação, acaba por não mais ser instrumento hábil para lidar com as diversas complexidades e contingências dos problemas sociais que possuem envergadura global.

De outro modo, também não corresponde às necessidades atuais a proposta de criação de uma constituição de alcance global, uma vez que a complexidade dos problemas sociais e a natureza cada vez mais especializada e técnica dos demais subsistemas, tornam obsoleta a proposta do direito impor um processo de regulamentação que apenas preserva a mesma dinâmica aplicada à proposta do constitucionalismo gestado pelo Estado-nação, mas em proporções mais abrangentes.

Deste modo, o autor propõe uma terceira linha, que não se revela como sendo o meio termo das propostas anteriores, mas sim um caminho completamente diverso e que se fundamenta a partir da Teoria dos Sistemas e de uma compreensão sociológica da constituição.

A particularidade desta proposta ocorre porque não dialoga apenas com o direito e a política, mas sim com todos os âmbitos da sociedade. Uma das vantagens que o autor assinala em relação a esta perspectiva é de que ela reconhece a existência de um direito informal, isto é, produzido para além dos limites das instituições estatais, usualmente compreendidas como fontes sociais autorizadas (TEUBNER, 2016).

Deste modo, ainda em conformidade com Teubner (2016), tem-se um direito que se operacionaliza a partir de diversos outros sistemas parciais autônomos, como a economia, a educação e os meios de comunicação em massa, o que permite uma aproximação mais rente da realidade complexa com que tais sistemas operacionalizam. A diversidade de matrizes normativas que são entendidas como legitimadas nesta perspectiva é o que define o pluralismo jurídico em Teubner (ROCHA, 2008).

Ao retomar o conceito de policontextualidade, já presente na obra de Luhmann, Teubner assevera que o direito contemporâneo é produzido a partir de vários contextos, isto é, concebe-se um mundo onde "o direito é fragmentado em um pluralismo em que o Estado é apenas mais uma de suas organizações" (ROCHA, 2012, p. 20). 
Admitir a premissa do pluralismo constitucional, nestes termos, tem especial importância para a análise que se pretende estabelecer em relação à prática da propaganda eleitoral nas redes sociais, uma vez que há uma ruptura paradigmática importante quanto à teoria do direito e afeta como a tutela jurídica destes conteúdos pode ser realizada. Isso porque um dos principais horizontes da dogmática jurídica contemporânea é o enfrentamento de desafios relacionados ao processo da globalização.

Neste sentido, Teubner (2016) pontua três fenômenos que evidenciam a vulnerabilidade da política internacional e que são usualmente considerados pelas outras correntes do pensamento jurídico contemporâneo. Em um primeiro momento, reconhece-se a desconstitucionalização do Estado nacional, em virtude de parte de suas funções estarem se projetando cada vez mais em um âmbito transnacional e sendo assumidas por atores nãoestatais. Em um segundo momento é possível assinalar que a atuação dos Estados hoje, em vários aspectos, como o ambiental por exemplo, pode ter consequências extraterritoriais, o que vulnerabiliza a legitimação democrática de tais ações. Por fim, em um terceiro momento, se reconhece que há um grande déficit democrático para que se estabeleça a existência de uma governance global.

No entanto, Teubner (2016) alerta que este tipo de análise, que se alicerça a partir dos fenômenos pontuados, parte da premissa de que há um vácuo legislativo no espaço transnacional. Precisamente neste ponto é que reside a controvérsia entre os que reconhecem a crise do Estado-nação e a proposta desenvolvida pelo autor.

Assim, nega-se a existência do vácuo constitucional transnacional por se reconhecer que com o passar das décadas do processo de globalização, especialmente a econômica, já se tornou possível reconhecer uma vasta trama legislativa, que viabiliza as interações de diferentes atores, como o Fundo Monetário Internacional, a Organização Mundial do Comércio e o Banco Mundial, por exemplo (TEUBNER, 2016).

Além da economia, também a internet demonstra elementos caracterizadores de uma constituição autônoma, inclusive com a possibilidade e necessidade de se refletir a respeito da aplicação dos direitos fundamentais no ciberespaço (ROCHA; COSTA, 2018).

Apesar da ênfase da análise de Teubner ser em relação à constituição econômica e da internet, o autor também reconhece que a religião, a ciência e a economia são sistemas parciais já estabelecidos, quanto à sua diferenciação em relação ao Estado-nação e constituições parciais respectivas. Neste contraste, se revela a necessidade de uma proposta paradigmática do 
direito que amplie o escopo da análise e permita a integração dos diferentes subsistemas em um âmbito mais abrangente.

Portanto, admitindo a existência de constituições parciais, a preocupação da teoria do direito ante o cenário transnacional no contexto contemporâneo não é mais a de propor a construção de uma ordem jurídica desde o início, mas sim de reformar o que já existe, reconhecendo a complexidade própria deste contexto (TEUBNER, 2016).

Assim, é a partir dessa realidade fragmentada e plural, que diversas fontes estabelecem e operam o direito. Não cabe, portanto, a imposição de conteúdos que se introjetam no sistema jurídico a partir apenas da atuação do Estado ou da comunidade de Estados, uma vez que tal esforço seria inócuo.

Deste modo, o limite do possível para a concepção de uma constituição mundial seria a proposta do direito de interligação das constituições próprias dos vários fragmentos globais. Isto é, um direito constitucional de colisões (TEUBER, 2016).

No entanto, o processo de constitucionalização fragmentada em curso não estabelece premissas decisórias específicas, nem garantias fundamentais a priori. Isso ocorre porque os sistemas operacionais são desprovidos de capacidade auto-organizativa no sentido de institucionalização. Deste modo, é apenas a interação das relações funcionais que promove a constitucionalização dos sistemas ao redor do mundo (TEUBER, 2016).

No entanto, em um mundo onde o desenvolvimento de um direito ocorre por meio de uma trama cada vez mais complexa de vários subsistemas abertos cognoscitivamente à comunicação de outros subsistemas, podendo sofrer irritações e transformações de suas operações, qual seria a margem para o reconhecimento de conteúdos como os direitos fundamentais?

No espaço da globalidade, Teubner (2016) reconhece apenas não apenas a possibilidade da criação de ilhas de constitucionalidade, mediante a existência de ordens autônomas de natureza estatal, mas também de instituições sociais não-estatais autônomas. Tal configuração ressignifica o papel do direito e as possiblidades das tutelas jurídicas da propaganda eleitoral nas redes sociais, conforme será abordado no próximo item.

\section{A aplicação da Teoria dos Sistemas Sociais Autopoiéticos em relação à propaganda eleitoral}


Para as finalidades do presente estudo, serão abordadas de forma específica duas das maiores redes sociais do mundo: o Facebook e o Twitter. Tal recorte se justifica, por um lado, mediante a impossibilidade técnica de se apurar todas as redes sociais atualmente em funcionamento e, por outro, em virtude da relevância que ambas as redes sociais possuem no contexto brasileiro.

O Facebook possui hoje, conforme Clement, (2020), 2,498 bilhões de usuários ao redor do mundo. Já o Brasil, conforme Cuponation (2019a), é o terceiro país com maior número de usuários com aproximadamente 130 milhões, ficando atrás apenas da Índia com 300 milhões e dos Estados Unidos com 210 milhões de usuários conectados à rede. Por sua vez, estima-se que o Twitter tenha hoje cerca de 8,28 milhões de usuários brasileiros (CUPONATION, 2019b).

Em relação à tolerância a respeito das propagandas eleitorais, a atual posição do Facebook é de não as proibir, enquanto que o Twitter decidiu pela vedação da prática no âmbito de suas operações.

O Facebook (2019) apresenta hoje um protocolo para a permissão de divulgação de anúncios de natureza eleitoral. Para tanto, é necessário que o interessado apresente um endereço no território brasileiro por meio de um comprovante de residência. Tal informação será confirmada pela própria rede social que identifica o local recorrente de acesso do usuário por ocasião do login. A pessoa responsável pela veiculação dos conteúdos precisará também se identificar com documento de identidade e o número de inscrição no Cadastro de Pessoas Físicas da Fazenda Federal.

Por sua vez, o Twitter comunicou através do perfil na própria rede de um dos seus criadores, Jack Dorsey (2019), que baniu os conteúdos de propaganda política em todo o mundo. As razões para tanto foram elencadas a partir do argumento de que a propaganda política não deve ser comprada, isto é, sofrer afetações mediante o poder de influência econômica do candidato, mas conquistada pelo político que pretende se comunicar com seus eleitores.

A suspensão da prática de anúncios pagos no Twitter se estende não apenas a candidatos, mas a toda ideia de divulgação relacionada a conteúdo de natureza política, segundo o anunciado, sob a argumentação de que não seria justo vedar apenas o anúncio de natureza eleitoral, mas permitir a veiculação de informações a respeito dessa temática que 
usualmente estão relacionadas à disseminação de fake news e que são amplamente potencializadas pelo grau de eficiência comunicativa da rede.

Partindo da consideração que as redes sociais são, em si, um sistema social próprio, aplicam-se aqui os conceitos desenvolvidos no capítulo anterior. Portanto, tem-se uma estrutura operacional específica, que pode ou não reagir em relação às irritações do meio de acordo com a lógica de funcionamento que lhe é específica.

No histórico de relacionamento entre os Estados e empresas que atuam a partir da lógica da internet, há alguns episódios paradigmáticos. Por exemplo, o Uber, aplicativo destinado à mobilidade urbana, declarou o encerramento de suas atividades na Colômbia em virtude de uma decisão da Superintendência da Indústria e do Comércio que determinou a suspensão das atividades da empresa, por considerar que a sua estrutura de operação faz com que esta conflite com os sindicatos dos taxistas pelo fato de que sua tecnologia acaba violando, de acordo com a decisão, as normas que regulamentam o mercado de transporte naquele país, o que geraria uma vantagem significativa e desvio de clientela (TORRADO, 2020).

Neste caso, o Estado colombiano manteve a postura tradicional de supremacia hierárquica de sua fonte normativa em detrimento da constituição própria do sistema de transportes por aplicativo. Porém, ao forçar o reconhecimento de sua própria constituição em detrimento da privada, acabou por destruir o elemento diferencial e o espaço de operação próprio da empresa naquele ambiente.

Outro exemplo que se pode considerar de imbricação entre a atividade de um Estado e as redes sociais contemporâneas são os casos envolvendo a discussão da possibilidade de interceptação das conversas realizadas entre os usuários de WhatsApp no Brasil.

Em um destes casos, o entrave se estabeleceu após a determinação, por parte do Poder Judiciário, de apresentação das conversas de algumas pessoas que eram alvos de uma investigação criminal. Como a empresa alegou que não armazena as informações dos usuários, não pode cumprir a decisão, o que implicou na decisão de suspender o aplicativo em todo o território nacional por parte da Magistrada responsável pelo caso (CONJUR, 2016).

Posteriormente à liminar, a decisão foi reformada e houve a normalização do serviço de mensagens. De todo modo, ainda a discussão permanece no âmbito da suprema corte brasileira pela Ação Direta de Inconstitucionalidade 5527 e pela Arguição de Descumprimento de Preceito Fundamento 403, ambas sem decisões definitivas (STF, 2020). 
Um diferencial que se destaca entre o caso colombiano e o brasileiro é que, no caso das ações que tramitam perante o Supremo, houve a abertura de participação de um representante do WhatsApp que, em sede de audiência pública, prestou esclarecimento de natureza técnica em relação às possiblidades e limitações técnicas do sistema do aplicativo, asseverando sobre a impossibilidade de que a quebra de sigilo seja realizada de forma repentina, como seria no caso das empresas de telefonia, e também como foi determinado anteriormente pela decisão menciona (STF, 2017).

Independentemente do desfecho quanto ao mérito das ações de controle concentrado que se encontram em tramitação no Supremo Tribunal Federal (STF), há que se reconhecer os limites para o exercício do poder estatal nestes casos. Isto é, não é mais possível, seja pela complexidade das novas tecnologias ou mesmo pela limitação da dinâmica do poder estatal, que se pretendam decisões de hierarquia, como se concebia sob os fundamentos do Estadonação.

Mas, poder-se-ia questionar que existe no cerne da discussão que permeia a possibilidade de propaganda eleitoral nas redes sociais, conteúdos eminentemente associados ao exercício dos direitos fundamentais. Assim, se, por um lado, é possível o acesso à propaganda eleitoral gratuita nas emissoras de rádio e televisão, por que também não se poderia pensar um espaço privilegiado para o exercício de anúncios no Twitter ou em regras distintas das adotadas pelo Facebook, já que tais conteúdos podem ser pensados como concretizadores de direitos fundamentais à medida que se relacionam com os direitos políticos? Para responder a este questionamento é preciso que se reflita a respeito da eficácia horizontal dos direitos fundamentais a partir da Teoria dos Sistemas.

Em um primeiro momento, há a necessidade de indagação se os atores privados transnacionais estariam vinculados aos direitos fundamentais. Isso se justifica porque os direitos fundamentais nasceram em um contexto de proteção das pessoas ou grupos de pessoas frente ao Estado, que figura, via de regra, como destinatário principal destes comandos, em um contexto social completamente diferente do que se estabelece hoje.

A resposta a respeito da vinculação é afirmativa. Porém, sob os fundamentos teóricos aqui apresentados, não é possível que o estabelecimento do conteúdo dos direitos fundamentais ocorra mediante o mesmo processo de sua institucionalização pelo Estado-nação. A um, porque uma generalização desse conteúdo que se funde nas ciências humanas ou na filosofia moral, como foi, por exemplo, o jusnaturalismo, não abarca a complexidade dos vários setores da 
racionalidade global. A dois, também não seria possível estabelecer a reespecificação necessária a partir da lógica de funcionamento do direito privado, igualmente insuficiente para a tarefa (TEUBNER, 2016).

Para que seja possível a eficácia dos direitos fundamentais sob estes termos, é preciso que haja a desvinculação de sua produção do sistema do poder político e que seja, assim, construída a generalização a partir de outros meios de comunicação social realmente eficazes (TEUBNER, 2016).

Ao renunciar a dependência exclusiva do sistema político ou mesmo a hierarquia de valores que subjaz ao direito privado, Teubner (2016) pretende estabelecer que os conteúdos de direitos fundamentais reconhecidos por cada um dos sistemas devem seguir a autonormatividade das respectivas instituições sociais, que moldam seus conteúdos a partir da função operativa específica. Desta forma, por exemplo, os critérios de não-discriminação no âmbito das escolas e universidade privadas são estabelecidos a partir de sua tarefa pedagógica e não sob os fundamentos da normatividade estatal. Assim, "em cada constituição parcial respectiva, o meio de comunicação singular - dinheiro, direito, ciência - deve ser diluído em posições de direitos fundamentais distribuídas de forma descentralizada" (TEUBNER, 2016, p. 245).

Ao comentar de forma mais específica em relação aos exercício dos poderes políticos Teubner (2016, p. 248) reconhece que "o direito ao voto e os direitos civis políticos possibilitam que o acesso ao meio poder mantenha-se aberto à toda a população", de forma a reconhecer que tal abertura ao poder, pelo exercício de participação, deva ser preservada como decorrência de um princípio político de inclusão.

No entanto, o autor reconhece que tal abertura não pode, em toda a sua generalidade, se tornar uma garantia de acesso a todas as instituições da sociedade como decorrência de uma imposição do poder político, justamente porque a diferenciação funcional dos sistemas sociais, bem como as determinações de inclusão e exclusão respectivas, não estão mais associadas a um centro de tomada de decisões como antes.

Neste sentido, Teubner (2016) sustenta que a internet pode ser compreendida como um bem comum artificial, regido pela neutralidade técnica, que implica dizer que a estrutura da rede tende a impedir obstáculos de acesso para a sua utilização. Porém, tal neutralidade é agredida quando os provedores estabelecem restrições de acesso ou concedem prioridade aos usuários que pagam mais caro. Neste sentido: “a eficácia horizontal em relação a terceiros na 
forma de um direito de acesso deveria fazer com que as obrigações de tolerância ou obrigações decorrentes de contratação sobreponham-se à propriedade privada da rede" (TEUBNER, 2016, p. 250).

Semelhante afirmação, em uma análise mais superficial, poderia levar à conclusão de que sendo a internet um bem comum e que o acesso possui eficácia horizontal, de que estaria legitimada a atuação estatal que tenha por escopo assegurar a intervenção necessária para a efetivação da garantia referida e do uso, nos termos concebidos pela constituição estatal. Partindo desta consideração, poderia o poder judiciário obrigar o Twitter a veicular as propagandas de conteúdo político que optou por não fazer? Poderia o Poder Judiciário determinar a veiculação de propaganda eleitoral que não siga os critérios estabelecidos pelo Facebook?

A respeito da possibilidade de judicialização, Teubner sustenta em sua obra a impossibilidade da busca por uma realidade ideal de justiça no contexto dos sistemas sociais. $\mathrm{O}$ que seria possível, neste propósito, é apenas a judicialização para limitar situações de injustiça: "A justiça dos direitos humanos pode, então, na melhor das hipóteses, ser formulada de maneira negativa. Ela é direcionada ao afastamento de situações inusitadas, não à perfeição de situações justas" (TEUBNER, 2016, p. 265).

Assim, ao refutar a intervenção estatal sob as concepções do Estado-nação, bem como renunciar à hierarquia de valores que o direito privado estabelece como critério para generalização da aplicação dos direitos fundamentais, Teubner (2016) propõe o conceito de sustentabilidade.

Considerando que não há uma terceira instância para a lógica organização heterárquica, que pressupõe a coexistência de diferentes ordens constitucionais e que se funda a partir dos Sistemas Sociais, remetendo-se ainda à ideia de um direito constitucional de colisões, o papel do direito seria apenas o de estruturar procedimentos de cooperação (TEUBNER, 2016).

Se por um lado, adotando-se essa concepção há, em certo sentido, uma ausência de obrigatoriedade da tomada de decisão por parte dos sistemas sociais autônomos, por outro lado, esta concepção viabiliza a formação de consensos. Precisamente a partir da busca de tais consensos é que se estabelece o princípio da sustentabilidade, de acordo com Rocha; Costa (2016), que surge como uma definição de justiça possível ante os diferentes sistemas constitucionalizados. Esta perspectiva corresponde a uma solução interna a partir da operação de cada sistema, mas que permite a heterorreferênciação quanto àquilo que passa no ambiente 
social. Dito de outro modo, é o conceito de justiça que se constrói a partir do reconhecimento das diferentes racionalidades estruturadas no âmbito dos vários sistemas sociais.

Tem-se assim a busca por um ato de equilíbrio que considere os efeitos mútuos em relação a ambas racionalidades operativas: "não por acaso, um tal ato de equilíbrio sobre a fronteira entre a manutenção do sistema e a promoção do ambiente deve ser considerado para seus efeitos mútuos, levando-se em conta igualmente ambos” (TEUBNER, 2016, p. 303).

Portanto, refletida a questão da tutela jurídica da propaganda eleitoral no âmbito das redes sociais a partir das lentes conceituais da teoria dos sistemas, conclui-se que não há que se pensar mais em uma referência mandatória por parte do direito estatal, incluindo o Poder Judiciário, mas sim da busca de coparticipação e diálogo entre as diferentes instituições para que, se necessário, os limites e estruturas de cada sistema sejam redefinidos a partir da abertura cognoscitiva.

\section{Conclusão}

Ao se admitir que o Estado-nação não possui mais o condão de tutelar a sociedade complexa, por seus vários limites institucionais e da próprio teoria de direito e da política que o estruturou, tem-se que os desafios apresentados pela sociedade globalizada impelem o Estado para uma atuação heterárquica, que reconhece a existência do sistema político e jurídico como sendo mais uns dos vários subsistemas que compõem o Sistema Social.

Deste modo, a relação do Estado com as redes sociais, sistemas sociais com regras desenvolvidas per se, deve seguir a busca de consensos operativos, sob pena de que uma atuação interventora por parte do ente público se subverta em agressão que leve o acesso à rede ou mesmo a sua existência a um colapso, como ocorreu no caso do Uber na Colômbia ou mesmo na impossibilidade de cumprimento da decisão judicial de intercepção das mensagens do WhatsApp que levou a suspensão do aplicativo em todo o território brasileiro.

Não obstante, a propaganda eleitoral estar diretamente associada aos direitos da cidadania, pela legislação eleitoral brasileira, não é possível, de forma inadvertida, estender a obrigatoriedade da veiculação de anúncios eleitorais no âmbito das redes sociais, como o Facebook e o Twitter, para além das determinações autorreferentes, sob pena de que os exemplos anteriormente mencionados venham a se repetir. 
Por certo que o reconhecimento da impossibilidade de atuação imperativa por parte do Estado não impede a possibilidade de que as comunicações entre o sistema jurídico, político e das redes sociais gere alterações estruturais daquele sistema, de forma a incorporar maior ou menor flexibilidade em relação aos conteúdos veiculados e suas regras. No entanto, tal alternativa tem que ser construída a partir do paradigma de um direito reflexivo, que se sirva para coordenar a possibilidade de diálogo entre os diferentes sistemas com constituições e racionalidades próprias.

\section{Referências bibliográficas}

BICCA, Luiz. Racionalidade, modernidade e subjetividade. São Paulo: Loyola, 1997.

BRASIL. Constituição da República Federativa do Brasil. Promulgada em 05.10.1988. Disponível em http://www.planalto.gov.br/ccivil_03/constituicao/constituicao.htm. Acesso em 18.01.2020.

BRASIL. Lei 12.034/2009 de 29 de setembro de 2.009. Altera as Leis nos 9.096, de 19 de setembro de 1995 - Lei dos Partidos Políticos, 9.504, de 30 de setembro de 1997, que estabelece normas para as eleições, e 4.737, de 15 de julho de 1965 - Código Eleitoral.

Disponível em http://www.planalto.gov.br/ccivil_03/_Ato2007-2010/2009/Lei/L12034.htm. Acesso em 19.01.2020.

BRASIL. Lei 9.504 de 30 de setembro de 1997. Estabelece normas para as eleições. Disponível em http://www.planalto.gov.br/ccivil_03/leis/19504.htm. Acesso em 19.01.2019.

BRASIL. Núcleo de Informação e Coordenação do Ponto BR. História. Disponível em https://www.nic.br/historia/. 201?. Acesso em 15.04.2020.

BRASIL. Supremo Tribunal Federal. Ação Direta de Inconstitucionalidade 5.527. Audiência Pública. Disponível em

http://www.stf.jus.br/arquivo/cms/audienciasPublicas/anexo/ADI5527ADPF403AudinciaPblica MarcoCivildaInterneteBloqueioJudicialdoWhatsApp.pdf. Acesso em 25.01.2020.

BRASIL. Supremo Tribunal Federal. Andamentos processuais da Ação Direta de Inconstitucionalidade 5.527. Disponível em

http://portal.stf.jus.br/processos/detalhe.asp?incidente=4983282. Acesso em 15.04.2020.

CLEMENT, J. Facebook: Number of monthly active Facebook users worldwide as of 3rd quarter 2019. Statista. 19.11.2019. Disponível em https://www.statista.com/statistics/264810/number-of-monthly-active-facebook-usersworldwide/. Acesso em 15.04.2020. 
CUPONATION. Brasil está entre os dez países com mais usuários no Twitter. Dispopnível em https://www.cuponation.com.br/insights/twitter-2019 Acesso em 25.01.2020.

CUPONATION. Usuários do Facebook. Disponível em

https://www.cuponation.com.br/insights/facebook-users. Acesso em 25.01.2020.

DORSEY, Jack Patrick. Twitter. Disponível em

https://twitter.com/jack/status/1189634360472829952. Acesso em 25.01.2020.

FACEBOOK. Central de Ajuda. Anúncios relacionados a temas sociais, eleições ou política. Disponível em

https://www.facebook.com/business/help/208949576550051?id=288762101909005. Acesso

em 25.01.2020.

GOMES, José Jairo. Direito eleitoral. 15. ed. São Paulo: Atlas, 2019.

HJARVARD, Stig. A midiatização da cultura e da sociedade. Trad. André de Godoy Vieira. Unisinos: São Leopoldo, 2014

LOSANO, Mario. Sistema e estrutura no direito: do século XX à pós-modernidade. Vol. 3 . Trad. Carlo Alberto Dastoli. São Paulo: Martins Fontes, 2011.

LUHMANN, Niklas. El derecho de la sociedade. 2. ed. Trad. Javier Torres. México, D.F.: Herder: Universidad Iberoamericana, 2005.

LUHMANN, Niklas. Introdução à teoria dos sistemas. Trad. Ana Cristina Arantes. Petrópolis: Vozes, 2009.

LUHMANN, Niklas. Law as social system. Trad. Klaus A. Ziegert. Oxfordshire: Oxford, 2004.

REVISTA CONSULTOR JURÍDICO (CONJUR). Juíza do RJ manda suspender WhatsApp e reclama de resposta em inglês. 19.06.2016. Disponível em

https://www.conjur.com.br/2016-jul-19/juiza-manda-suspender-whatsapp-reclama-respostaingles . Acesso em 25.01.2020.

ROCHA, Leonel Severo da. Autopoiese e teoria do direito. In: SCHWARTZ, Germano. Judicialização das esferas sociais e fragmentação do direito na sociedade contemporânea. Porto Alegre: Livraria do Advogado, 2012. p. 9-28.

ROCHA, Leonel Severo da. Epistemologia jurídica e democracia. São Leopoldo: Unisinos, 1998. $164 \mathrm{p}$.

ROCHA, Leonel Severo da. Uma nova forma para a observação do direito globalizado: policontextualidade jurídica e estado ambiental. In: STRECK, Lenio Luiz; MORAIS, José Luis Bolzan (org.) Constituição, Sistemas e Hermenêutica: programa de pós-gradução em direito da Unisinos. N. 05. 2008. 
ROCHA, Leonel Severo; COSTA, Bernardo Leandro Carvalho. Constitucionalismo social: constituição na globalização. Curitiba: Apris, 2018. p. 34.

TEUBNER, Gunther. Fragmentos constitucionais: constitucionalismo social na globalização. São Paulo: Saraiva, 2016. P. 27.

TORRADO, Santiago. Uber sairá da Colômbia a partir de fevereiro. El País. 12.01.2020.

Disponível em https://brasil.elpais.com/economia/2020-01-12/uber-saira-da-colombia-a-partirde-fevereiro.html. Acesso em 25.01.2020.

TWITTER. Twitter detalha medidas contra uso indevido de robôs e desinformação.

Disponível em https://blog.twitter.com/pt_br/topics/company/2017/twitter-detalha-medidas-contra-usoindevido-de-robos-e-desinformacao.html. Acesso em 21.04.2020. 